\title{
Contractual methods for dispute avoidance and resolution (DAR)
}

\author{
M. Osama Jannadia ${ }^{\mathrm{a}, *}$, Sadi Assaf ${ }^{\mathrm{b}}$, A. A. Bubshait ${ }^{\mathrm{b}}$, Allam Naji ${ }^{\mathrm{b}}$ \\ ${ }^{a}$ College of Environmental Design, King Fahd University of Petroleum and Minerals, Dhahran, 31261, Saudi Arabia \\ ${ }^{\mathrm{b}}$ Department of Construction Engineering and Management, King Fahd University of Petroleum and Minerals, Dhahran, 31261, Saudi Arabia
}

\begin{abstract}
This paper discusses the appropriateness of contractual methods towards dispute avoidance and resolution (DAR) for industrial projects in Saudi Arabia. It focuses on the private industrial sector in the Eastern Province. A survey was conducted using the principles of quota sampling where 93 questionnaires were distributed to 11 owners, 59 contractors and 23 consultants. The survey consisted of 20 statements that measured the parties' attitude and opinion towards contractual methods recommended for dispute avoidance and resolution (DAR) during the construction phase. Respondents indicated their level of agreement on a 5-level scale. The results reflect the appropriateness of these techniques for industrial projects. The five contract administration methods for dispute avoidance and resolution (DAR) covered in this study are: Allocating Fair Contract Risk, Drafting Dispute Clauses, Team Building, Provision of a Neutral Arbitrator, and Binding Arbitration. (C) 1999 Elsevier Science Ltd and IPMA. All rights reserved.
\end{abstract}

Keywords: Contract; Disputes; Industrial projects; Saudi Arabia

\section{Introduction}

During the past two decades, serious disputes concerning construction contracts have become increasingly common on construction projects in Saudi Arabia $[1,2]$. It is common practice for designers, contractors and owners to negotiate small and uncomplicated disputes, but larger and more complex ones frequently hinder the project through involvement with lengthy legal issues. Typically, if the parties cannot reach a resolution themselves, expensive, time-consuming legal procedures begin, which severely affects all the participants. Disputes are a reality in every construction project. Without the means to address them, minor issues can fester and grow, with crippling consequences for project participants. The rising cost, delay and risk of litigation in construction disputes has

\footnotetext{
* Corresponding author. Tel.: +966-3-860-3590; fax: +966-3-8602539 .

E-mail address: jannadi@kfupm.edu.sa (M. O. Jannadia)
}

prompted the construction industry to look for new and more efficient ways to resolve these disputes outside the courts.

Within the past decade, the Construction industry in the US has taken steps to avoid litigation and to control disputes by developing and employing various mechanisms for alternative dispute resolution that can be implemented during almost any stage of a construction project [3]. These mechanisms range from simple negotiation to binding arbitration. Experience has shown that when resolution occurs sooner rather than later and when this resolution is relatively unconfrontational, there is a much better chance that litigation can be avoided. Waiting until the end of a project to address a dispute inevitably makes it harder and more expensive to resolve. Parties involved in a construction dispute, or indeed any commercial dispute, generally prefer to retain control over the outcome and maintain a working business relationship.

The objective of this study is to evaluate the appropriateness of the contractual methods elucidated below for industrial projects in Saudi Arabia. 


\section{Contractual methods for DAR}

As the number of claims and resulting disputes on construction projects has exploded, the sheer cost and delay of resorting to court systems in any country has led to the emergence of various Alternative Dispute Resolution (ADR) approaches [4]. The construction industry has shown a marked preference towards ADR instead of Litigation for five principal reasons: Speed, Cost, Expertise, Privacy and Practicality [3]. ADR approaches normally take place outside the legal system.

There are many techniques that can be incorporated in preparing construction contracts so as to avoid disputes and, of course, costly and time-consuming litigation. The contract administration methods covered in this study for dispute avoidance and resolutions (DAR) are [5]:

1. Allocating fair contract risk.

2. Drafting dispute clauses.

3. Team building.

4. Provision of a neutral arbitrator.

5. Binding arbitration.

\subsection{Allocating fair contract risk}

It is common local practice for architects/engineers (A/E) to prepare construction contract documents simply by adding to or deleting from a set of previously employed contract documents, and while this cut-and-paste method may save time in preparing the construction contract, it often leads to problems, since documents are not read and prepared as a whole for the specific project. Such practices increase the unforeseen risks for the contractor. It comes as no surprise that parties to a contract often include contract language designed to shift risk to the other party so that the bases for claims and disputes are eliminated [5]. For example, making a contractor responsible for the impact of unanticipated site conditions may effectively preclude recovery of additional costs caused by such conditions. Similarly, contract dispute clauses can be drafted so that even the submission of a valid claim is made nearly impossible, a practice which actually encourages litigation. Such contract provisions, however, do not prevent disputes from occurring. Often, they only create fractious relationships among the parties involved in the project. Construction-project owners generally have two concerns when they shift unanticipated risks to a contractor. As a result of this risk transfer, the following may occur:
- The contractor will build a contingency into the price to cover the risk; or,

- He will not have a contingency and will face financial problems.

Unfair shifting of risk, transferring of all responsibility on a party that is not generally expected to control that risk, can result in that party having to spend time and effort looking for ways to stay alive in the project, usually to the detriment of the project itself. As the costs and risks of construction continue to rise, more construction-industry professionals are turning to a system that fairly distributes risk among all the parties involved, the architect/engineer, the owner, the contractor and the sub-contractor(s). Fairness is an elusive concept, but the objective as defined here is to allocate the risk to the party best able to control it. An equitable contract serves as the first step in building cooperation and close coordination among the project participants, and providing a strong foundation for working out the inevitable disputes before they lead to divisive claims that can negatively affect the schedule and cost of construction.

\subsection{Drafting dispute resolution clauses}

In addition to identifying responsibilities and allocating risks, a contract should contain language for addressing disputes and claims at the relevant stage in a project [5]. This includes clauses containing explicit provisions and instructions for parties to resolve disputes as they arise, during the course of the project. For example, provision for a binding resolution can include dispute resolution arbitration under the American Arbitration Association (AAA) Construction Arbitration Rules. Contractual provisions should always require that parties first try to settle all disputes by some non-binding techniques, such as mediation. The American Institute of Architects, the Associated General Contractors of America and the American Arbitration Association have each published suggested guidelines and model contract terms for each provision. The guidelines can be helpful in tailoring the dispute-resolution provisions of a contract to each specific need. The contract language can also be drafted in such a way as to emphasize the notice provisions, which are of paramount importance. The essential elements contained in most notice provisions are: the form of communication, the individual or organization to which the notice should be directed, the time limits, and other procedures to be followed [6].

Less frequently the contract may require an assertion that additional compensation or time is expected. Often, the contract will contain references to the change clause for additional guidance. 


\subsection{Team building}

Team building is another dispute-resolution technique that can be instituted at the beginning of a construction project to help allow for better cooperation and coordination among the parties [5]. One such process, partnering, has gained increasing popularity in recent years. It involves an extra contractual understanding among all parties to form a partnership of sorts to achieve mutually determined goals and objectives as well as to minimize disputes and claims. This agreement is often reached through a partnering workshop, wherein all parties agree to take specific steps to work together, fairly allocate risk and responsibilities and recognize their common goal-a successful project. Although partnering may initially require more manpower and effort, its benefits can be invaluable, creating a more harmonious, less confrontational process and, on completion, a successful project free of litigation and claims.

Partnering allows the parties to move from an adversarial relationship to cooperative team work, from a win-lose strategy to a win-win plan, from a stressful project to a satisfying one, from a litigation focus to solutions and accomplishments, and from finger-pointing to a hand-shake mind-set; it also allows bureaucratic inertia to dissolve and risk-taking to be endorsed [7].

In the past few years, a process called partnering realignment has evolved to help stakeholders deal with problems arising during the project, rather than resolving them in court after the project is completed [8]. This process, when embraced and carried through, has helped turn around troubled projects. Partnering realignment is a corrective process implemented during the project, to help organizations resolve issues, set a new course and maximize the remaining potential for success. It is an attempt to regain and retain control of the project and to plan ways of avoiding future problems.

\subsection{Provision of a neutral arbitrator}

The most careful planning cannot always prevent disputes and this step is the last chance to resolve a dispute before resorting to a binding settlement [5]. Providing for a neutral party to analyze issues and providing dispute resolution, if negotiations come to an impasse, is an important step towards minimizing the problems caused by disputes. This technique involves a pre-selected independent 'neutral' to serve the parties as an observer, fact finder and dispute resolver throughout the construction process. Ideally, a neutral is selected at the inception of the construction phase of the project to act immediately in resolving disputes that cannot be otherwise settled.
Although procedures for establishing a neutral vary and can be tailored to meet the specific needs of a project, they involve a few basic elements, including the following.

- The neutral must be acceptable to and compensated by both parties and must be both independent and impartial.

- The neutral is initially given an introduction to the nature, scope and purpose of the project and is furnished with the contract documents. The neutral is then required to regularly visit the project site, meet with key project personnel, and attend project meetings thus being kept informed of project progress.

- Whenever the parties are unable to resolve a dispute, it may be immediately referred to the neutral for a prompt non-binding decision.

- If the neutral is empowered to make only non-binding recommendations and his recommendation is challenged by either party, the recommendations can be admissible as evidence in a subsequent Alternative Dispute Resolution (ADR) proceeding or in a court of law.

Because the neutral is readily available and knowledgeable about the project, he can often help to mediate or encourage the prompt resolution of disputes. In addition, the time and cost saved by immediately addressing disputes can help to preserve the relationships among the parties and keep the project focused on mutual goals.

\subsection{Binding arbitration}

The construction industry, more than perhaps any other, has experience with using arbitration for resolving disputes [5]. Serious contract disputes involving huge cost overruns, long schedule delays and complicated technical specification requirements are, in many cases, best decided by experienced arbitrators. The construction industry's success in moving away from litigation is a valuable lesson to those who today are considering Alternative Dispute Resolution as a substitute for facing litigation, given the current 'crisis' in the civil courts. Even having taken the four preceding steps, some disputes will not be resolved. Turning the decision over to an arbitration panel comprised of knowledgeable and experienced industry professionals has many advantages over a judge and jury. Although once seen as the only option, binding arbitration is now considered a last resort, after equitable contracting, ongoing dispute resolution and non-binding Alternative Dispute Resolution techniques have failed.

As in litigation, the parties give up control over the decision and have to proceed in an adversarial forum, endangering future relationships. The perception, if 
not the reality in every case, is that arbitration has advantages over litigation, including lower cost, more prompt resolution and time saving [9]. Procedurally, a number of approaches to arbitration have been developed.

Perhaps one of the widely publicized forms is the model defined by the American Arbitration Association (AAA), the construction industry arbitration rules (CIAR), but special procedures have been established by other professional associations and individual owners and designers [10]. To date, most published studies of arbitration have focused on the underlying legal principles and not on its organization or performance. With expanded use of arbitration, there is also a rapid evolution in its form and greater interest in its performance. The following are key issues determining its form of application.

\subsubsection{Scope of disputes}

In practice, arbitration is frequently limited to specific topics and/or size of claims. The most common rationale for limiting the scope is that it permits the user to capitalize on the benefits of arbitration, such as a quick settlement, without risking large settlements or adverse interpretations of the contract provisions.

\subsubsection{Selection of arbitrators}

With binding arbitration, the arbitrators are the final interpreters of the dispute, and hence their selection is taken seriously by all the parties. There are basically three approaches to their selection. Arbitrators may be selected from a prepared list, from permanent board members, or they may be selected prior to the start of the construction project. Perhaps the simplest and most expedient arrangement is for a permanent established arbitration board to hear all disputes of a specified type coming before the owner [11].

\subsubsection{Settlement of disputes}

In principle, with an arbitrated dispute, the judge or arbitrator reviews facts and orders a fair settlement, which is all that is of interest to the parties. Arbitrators are relatively free to base their decisions upon legal or technical considerations, and may even set aside more formal legal precedents for a decision.

\section{Methodology}

The questionnaire containing 20 statements was designed by reviewing literature dealing with construction disputes. The significant factors taken in to account while designing questionnaires are: a) distribution of risk; b) expertise of arbitrators; and c) speed and cost. The questionnaire determines the attitudes of the respondents about the following contract administration techniques methods: (1) allocating fair contract risk; (2) drafting dispute clauses; (3) partnering as one way of team building; (4) provision of a neutral; (5) binding arbitration. These were distributed to industrial owners, contractors and $\mathrm{A} / \mathrm{Es}$, that form the population of the study with the limitations given in Table 1. The exhaustive population list was taken from the publications of the Chamber of Commerce and Industry [12 and 13].

The questionnaire statements were devised to measure the respondents' opinions by registering them on a 5-point scale ranging from 'always' to 'never', Appendix A. Each grouping of four statements measured one of the above methods; the grouping is as follows:

Statements 1, 2, 11 and 16 measure allocation of fair risk.

Statements 6, 7, 15, and 18 measure drafting dispute clauses.

Statements 3, 8, 12 and 17 measure building teams.

Statements 4, 9, 13 and 14 measure providing a neutral.

Statements 5, 10, 19 and 20 measure referring to arbitration.

Table 1

Population limitations

\begin{tabular}{llll}
\hline Limitations & Owners & Contractors & A/Es \\
\hline Private/public & Private & Private & Private \\
Location & Eastern province & Eastern province & Eastern province \\
Business category & Industrial & Building and industrial & Building and industrial \\
Min. active period & 5 years & - & - \\
Min. capital & SR 5000 & - & - \\
\hline
\end{tabular}

${ }^{\mathrm{a}} \mathrm{USD} 1=\mathrm{SR} 3.75$. 
Table 2

Stratified quota sample

\begin{tabular}{lllll}
\hline Stratum & $\begin{array}{l}\text { Stratum } \\
\text { population }\end{array}$ & $\begin{array}{l}\text { Stratum } \\
\text { size }\end{array}$ & $\begin{array}{l}\text { Prop. of } \\
\text { population }\end{array}$ \\
\hline Owners $\left(\mathrm{N}_{1}\right)$ & 58 & 11 & $\begin{array}{l}\text { Prop. of } \\
\text { sample }\end{array}$ \\
Contractors $\left(\mathrm{N}_{2}\right)$ & 357 & 59 & $19 \%$ & $11.8 \%$ \\
A/E's $\left(\mathrm{N}_{3}\right)$ & 126 & 23 & $17 \%$ & $63.4 \%$ \\
Total $(\mathrm{N})$ & 541 & 93 & $18 \%$ & $24.8 \%$ \\
\hline
\end{tabular}

\subsection{Sampling technique}

The concept of quota sampling was utilized in this study, whereby the respondent selection was non-random in the sense that the respondents did not have a known non-zero chance of being selected. Each respondent was selected and contacted, and a qualified person was selected by the responding firm to complete the questionnaire. This process was done until the sample 'quota' was almost satisfied. The advantage of this procedure while being faster and more cost effective is in the selection of the respondents by the researchers. Quota sampling allowed the researchers to select the potential respondents, not only meeting the limitations mentioned in Table 1, but representing a higher proportion, based upon their market share, of the construction industry than would have been possible in other sampling techniques. The following equation [14] was used to determine the required sample size, Table 2:

$n=\frac{\sum_{i=1}^{3} \frac{N_{i}^{2} p_{i} q_{i}}{w_{i}}}{N^{2} D \sum_{i=1}^{3} N_{i} p_{i} q_{i}}$

where an average value of $p=0.5$ and $q=0.5$ is selected to give the highest sample size. $D=0.0025$, and $w_{i}=N_{i} / N$. where $D$ is confidence limit of $95 \%$

\section{Results and discussion}

The twenty statements that formed the questionnaire were evaluated by assigning the following values to each response: a value of four was assigned to a response of 'always', three to 'mostly', two to 'sometimes', one to 'seldom', and a value of zero to a response of 'never'.

Results from owners were generated from 10 respondents to the questionnaires sent to 14 owners of industrial plants/factories, where the total population was 58 owners. Results from contractors were generated from 54 responses to the questionnaire sent to 75 contractors in the business of civil and industrial construction, where the total population was 357 contractors. Results from A/Es were generated from 22 respondents to the questionnaires sent to $23 \mathrm{~A} / \mathrm{Es}$, where the total population was 126 . While some of the respondents showed enthusiasm in responding to the survey, even sparing time to discuss their responses with the researchers, others officially declined to participate in the study causing the total response rate to drop from $17 \%$ to about $16 \%$. It is the opinion of the authors that the detailed discussions with the willing respondents regarding their responses provided the authors with more information regarding the study and more than compensated for the very slight drop in the response rate. Table 3 presents the complete results, based on the responses to grouped statements as stated in the research methodology.

Table 3

Responses to grouped statements on contractual methods

\begin{tabular}{|c|c|c|c|c|c|c|c|c|}
\hline Contractual method & Statement No. & Owner mean & Owner rank & Cont. mean & Cont. rank & $\mathrm{A} / \mathrm{E}$ mean & $\mathrm{A} / \mathrm{E}$ rank & Total mean \\
\hline Fair risk allocation & $1,2,11,16$ & 2.13 & 3.5 & 2.82 & 5 & 2.21 & 4 & 2.39 \\
\hline $\begin{array}{l}\text { Drafting dispute resolution } \\
\text { clauses }\end{array}$ & $6,7,15,18$ & 2.15 & 2 & 3.13 & 1 & 2.47 & 1 & 2.58 \\
\hline Team building & $3,8,12,17$ & 2.13 & 3.5 & 2.88 & 3.5 & 2.29 & 2 & 2.43 \\
\hline Provision of neutral & $4,9,13,14$ & 2.4 & 1 & 2.88 & 3.5 & 2.12 & 5 & 2.47 \\
\hline \multirow[t]{2}{*}{ Binding arbitration } & $5,10,19,20$ & 1.8 & 5 & 2.97 & 2 & 2.27 & 3 & 2.35 \\
\hline & Average mean & 2.12 & - & 2.94 & - & 2.27 & - & \\
\hline
\end{tabular}


The first group of statements measured the appropriateness of fair risk allocation in contract documents. The three parties showed a slight closeness in ranking their agreement. The low ranking of this contractual method is due to the fact that most respondents are uncertain about what areas may fall under their responsibilities. The respondents also appear to have adapted themselves to the prevalent local situation, where the risk is transferred to the other party. For example the situation where the owner transfers the risk of unknown site conditions to the contractor to which the contractor responds by adding an appropriate contingency to his bid.

The second group of statements measuring the appropriateness of drafting dispute resolution clauses reveals the closest agreement among the parties in their ranking. The results suggest a strong desire by the respondents to resolve disputes by defining dispute resolution procedures and responsibilities. This contractual method is ranked highly by all the parties.

The third group of statements measuring team building contractual provisions, such as partnering, ranked around the middle by the respondents revealing that the feeling of mistrust is still prevalent. A few years ago team building would rarely be suggested in the local construction industry, and if suggested would be regarded with suspicion. It is the belief of the researchers that it will take some years for this contractual method to be fully understood and accepted.

The high variation in ranking of the fourth group of statements, measuring the appropriateness of providing a neutral, by the respondents merits a discussion. The top ranking of this contractual method by the owners may due to their belief, as revealed in the discussions between the authors and some owners, that the $\mathrm{A} / \mathrm{E}$ should act as a neutral in case of any dispute. The A/ E being paid by the owner tend to be partial toward the owner in their judgment. These expectations by the owner of the $\mathrm{A} / \mathrm{E}$ is instrumental in moving the $\mathrm{A} / \mathrm{Es}$ in giving this contractual method the lowest ranking as a way of avoiding an ethical dilemma. The contractors are also naturally suspicious of this method.

The results of the fifth group of statements measuring the appropriateness of using binding arbitration also present an interesting picture. Most contracts prepared in Saudi Arabia, refer to the laws and regulations of the Kingdom, usually leaving little to refer in case of disputes to arbitration. Arbitration, moreover, presents a loss of authority in the eyes of the owners, thus their low ranking of this contractual method. The contractors on the other hand give this method a second ranking, as they prefer to have a speedy and low cost decision as it does not burden their finances compared to litigation. Moreover some arbitrators are known to give decisions based on their expertise and not on the contract documents.

Moreover the Average Mean (AM) of the three parties in Table 3 reveals the strong desire among the contractors $(\mathrm{AM}=2.94)$ compared to the other parties for practicing alternative dispute resolution (ADR) methods. This may be due to the fact that in the local construction industry the contractors are known to lose the most due to disputes and delay in their resolution. The owners $(\mathrm{AM}=2.12)$ are naturally conservative in practicing different contractual methods for resolving disputes as these methods are seen by them as a loss of authority. $\mathrm{A} / \mathrm{Es}(\mathrm{AM}=2.27)$ tend to only slightly favor the above mentioned contractual methods as compared to the owners due to their professional attitude but not strongly, as their fees are fixed in the contract and their capital is not tied up in the project.

\section{Conclusion}

The survey reveals a level of desire among the respondents towards the drafting of dispute resolution clauses, thus steps should be taken by the local construction industry for proper drafting of these clauses and publicizing their importance.

Strangely enough 'team building' is ranked higher than 'fair risk allocation'. Any team building exercise can succeed only if the parties practice fairness and build trust. The researchers believe that the owners need to be educated of this fact and convinced that fair risk allocation will save them money, otherwise they will be presented with inflated bids by contractors trying to be safe.

In the other two contractual methods, provision of a neutral and binding arbitration, the contractors with the help of the governmental authorities, in view of the owners' prejudice, could seek to establish an autonomous body, similar to the Dispute Avoidance and Resolution Team (DART) in the United States. This body could help in providing neutrals and decisions in referred arbitrational cases, besides developing and publicizing alternate dispute resolution (ADR) methods. The contractors have to take a firm step in the establishment of contractual methods for DAR, by insisting on their use in the contract documents, as they reveal a strong need to avoid and resolve disputes.

\section{Acknowledgements}

The authors would like to acknowledge the facilities provided by the King Fahd University of Petroleum and Minerals, Dhahran, Saudi Arabia in preparing this paper. 


\section{Appendix A Questionnaire}

This questionnaire is intended to determine your attitude to dispute resolutions without litigation in court rooms. Please tick the appropriate box.

1. Contracts should not shift all risks to one

ALWAYS MOSTLY SOMETIMES

SELDOM NEVER party. [ ]

[ ]

[ ]

[]

2. The contractor should not build a contingency [ ]

[ ]

[ ]

[ ]

[ ]

into his price to cover all risks.

3. The spirit of partnering should only be recog- [ ]

[ ]

[ ]

nized at high, down to the lowest level of the organization.

4. A "neutral" should not always encourage both parties to refer disputes to litigation.

[

[ ]

[]

[ ]

[ ]

5. Arbitrators consider their task to be of techni- [ ] cal experts applying their experience to the case rather than of pure fair and impartial hearing.

6. Contract clauses may allow any valid claim.

[ ]

7. Contractors should include a language for

[ ]

addressing disputes and claims.

8. Partnering does not lead to stressful project climate.

9. The owner should not select a "neutral" with- [ ] out the knowledge of the contractor.

10. Arbitration has advantages over litigation of lower cost and prompt resolution.

11. Construction contract documents should not be prepared by adding or deleting from a set of previous documents/standard contract.

12. Owner-Contractor partnering minimizes disputes and claims.

13. Providing for a neutral helps minimize problems caused by disputes.

14. A "neutral" saves time and money if chosen as a substitute for litigation.

15. Contracts should clarify when additional com- [ ] pensation or time is expected.

16. Fair allocation of risks helps focus on the pro- [ ] gress of the project. 
17. Partnering brings partners to equal bases in construction business.

18. The form of communication is an essential el- [ ] ement in notice provisions.

19. Arbitrators should not always be chosen by owners to ensure fair decisions.

20. The owner cannot terminate any arbitrator if found out making decisions not in the interest of the owner.
[ ]

[ ]

[ ]

[ ]

[ ]

[ ]

[ ]

[ ]

[ ]

[ ]

[ ]

[ ]

[ ]

[ ]

[ ]

[ ]

[ ]

[ ]

\section{References}

[1] Al-Barghouthi M. Liability allocation among the parties of fixed-price construction contractors in Saudi Arabia. M.Sc. Thesis, King Fahd University of Petroleum and Minerals, Dhahran, Saudi Arabia, 1994.

[2] Al-Subaie O. Construction claims in residential housing. M.Sc. Thesis, King Fahd University of Petroleum and Minerals, Dhahran, Saudi Arabia, 1987.

[3] Robert FC, John PB. Construction business handbook. New York: McGraw Hill, 1978.

[4] Nielsen KR. Patnering-application on international projects. The Nielsen-Wurster Group, Inc, 1994.

[5] Steen RH. Five steps to resolving construction disputes without litigation. Journal of Management in Engineering 1994;10(4):19-31.

[6] Thomas HR, Smith GR, Wright DE. Resolving disputes over contract notice requirements. Journal of Construction Engineering and Management 1990;116(4):738-55.

[7] Harback HF, Basham DL, Buhts RE. Partnering paradigm. Journal of Management 1994;20(1):23-7.

[8] Brown J. Partnering to save troubled projects. Journal of Management in Engineering 1994;10(3):22-5.

[9] Hester W, Kuprenas J, Thomas H. Arbitration: a look at its form and performance. Journal of Construction Engineering and Management 1900;113(3):353-67.

[10] Coulson R. Disputes management under modern construction systems. Law and Contemporary Problems 1983;46:127-35.

[11] Richards BJ. Enforceability of arbitration provisions and construction contracts. Federal Insurance Counsel Quarterly 1983;34:95-110

[12] Chamber of Commerce and Industry for the Eastern Province. Industrial Directory, Dammam., 1993.

[13] Chamber of Commerce and Industry for the Eastern Province. Trade Directory, Dammam., 1994.

[14] Scheaffer LR, Mendenhall W. Elementary Survey Sampling. Boston: PWS-Kent Publishing Co., 1990.

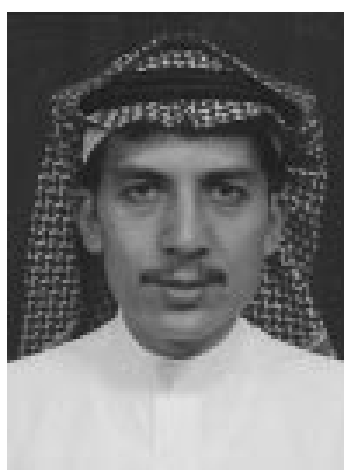

Dr. M. Osama Jannadi is the Dean of College of Environmental Design, King Fahd University of Petroleum and Minerals (KFUPM), Dhahran, Saudi Arabia. He received a Ph.D. in Construction Management from the George Washington University at Washington D.C., USA in 1989. Dr. Jannadi conducted many research papers and presented several seminars inside Saudi Arabia and abroad. Dr. Jannadi's areas of interest are construction safety, risk mangement, quantitative methods in construction, construction planning, scheduling and control. 


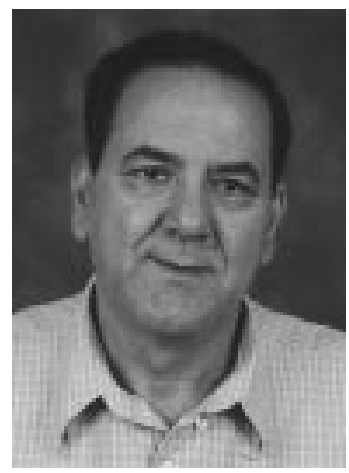

Dr. Sadi A. Assaf is an Associated Professor of Construction Engineering and Management at King Fahd University of Petroleum and Minerals (KFUPM). He obtained his Ph.D. in 1982 from the Unviersity of Illinois. His areas of specialization and interest are quantitative methods in construction, risk management, and lifecycle costing. Dr. Assaf has 12 years of professional experience in the planning, design, and construction of major engineering and construction projects in the US, and has 16 years of experience teaching and researching construction management at KFUPM. He has received the Distinguished Research and Teaching Awards at KFUPM several times.
Dr. Abdulaziz A. Bubshait is an Associated Professor of Construction Engineering and management at KFUPM. He received his Ph.D. from the University of Washington in Seattle, WA, in 1985. Dr. Bubshait's main areas of interest and research are construction quality assurance and construction methods and highway construction. $\mathrm{He}$ is a member of AACE International.

R. Allam Naji is a graduate student, Construction engineering and Management Department, King Fahd Unviersity of Petroleum and Minerals. He obtained a B.S. in Civil Engineering from KFUPM in 1982. 